

http://jyd. pitt. edu/ | Vol. 14 Issue 1 DOI 10.5195/jyd.2019.634 | ISSN 2325-4017 (online)

\title{
Positive Youth Development for Youth With Disabilities in a Therapeutic Camp Setting
}

\author{
Angela J. Wozencroft \\ University of Tennessee, Knoxville \\ awozenc1@utk.edu \\ Jason L. Scott \\ University of Tennessee, Knoxville \\ jlscott@utk.edu
}

Steven N. Waller

University of Tennessee, Knoxville

swaller2@utk.edu

Macie D. Parsons

University of Tennessee, Knoxville

mparsons3@vols.utk.edu

\begin{abstract}
The purpose of this article is to describe the value of the outdoor camp experiences among youth with disabilities participating in an outdoor therapeutic camp. The focus of the analysis is to understand the dimensions of positive youth development amongst youth campers with disabilities. A total of 12 campers were interviewed, 6 male and 6 female. Emerging themes included: (a) social, (b) character building, and (c) self-confidence and provide linkages to positive youth development domains. Findings identified the benefits that youth receive from attending an outdoor therapeutic recreation camp program such as opportunities to interact with old and new friends, feeling like a member for the camp family, feeling accepted and able to be themselves. Other benefits included becoming more independent, autonomous, and more self-confident.
\end{abstract}

Key words: disability, outdoor therapeutic camp, youth development

(c) $\mathbf{E Y}$ New articles in this journal are licensed under a Creative Commons Attribution 4.0 License. This journal is published by the University Library System, University of Pittsburgh and is cosponsored by the University of Pittsburgh Press. The Journal of Youth Development is the official peer-reviewed publication of the National Association of Extension 4-H Agents and the National AfterSchool Association. 


\section{Introduction}

Positive youth development (PYD) is a strengths-based approach to enhance youths' skills, interests, and abilities through a variety of programs and experiences (Hamilton, Hamilton, \& Pittman, 2004). Moreover, advocates of PYD posit that youth have an innate ability to thrive, and programming should be designed to promote this natural propensity (Duerden, Widmer, \& Witt, 2010). Participation in residential camps has demonstrated positive outcomes for youth development such as increases in independence, self-esteem and identity, and socialization skills (Gillard, Witt, \& Watts, 2011). Of particular concern is the impact the camp experience has on the development of youth with disabilities. More specifically, therapeutic camp settings offer youth with disabilities an opportunity similar to the nearly 10 million typically-developing youth participating in camp each year.

The field of therapeutic recreation (TR) utilizes activity-based interventions to reduce activity limitations and increase independence in life activities in a variety of settings such as outdoor recreation. Therapeutic recreation is a service designed to aid individuals in reaching their highest level of independence in life activities while helping to reduce the activity limitations that are caused by an illness or a disability (ATRA, n.d.). The purpose of this article is to describe the value of the outdoor camp experiences among youth with disabilities participating in a therapeutic camp setting. In addition, the authors seek to explain how positive youth development can be operationalized within the context of campers with disabilities. There is overwhelming research in the area of youth development through camp participation; however, the experiences of youth with disabilities is more limited. In particular, the developmental pathways of youth with disabilities require attention as the youth transition into young adulthood.

\section{Youth With Disabilities}

Between 2006 and 2008, about one in six children in the United States had a developmental disability ranging from mild disabilities such as speech and language impairments to serious developmental disabilities, such as intellectual disabilities, cerebral palsy, and autism (Centers for Disease Control and Prevention, n.d.). Furthermore, over two million adolescents in the United States have a form of chronic illness (Allsop, Negley, \& Sibthorp, 2013). As a result of these disabling conditions and the challenges associated with them, youths' lives can be greatly impacted leading to impaired physical, emotional, and social development as well as isolation, which increases the likelihood of behavioral problems during adolescence (Hamilton, 
Positive Youth Development at a Therapeutic Camp

Mazzucchelli, \& Sanders, 2015). In addition to the developmental implications, youth with disabilities are often more limited than their peers without disabilities in their opportunities to recreate and participate in typical activities. Outdoor therapeutic camps offer programs that seek to improve the overall quality of life of such youth.

\section{Outdoor Therapeutic Camps for Youth Development}

Generally, participation in camp provides youth with opportunities for leadership and sense of belonging, which is important to the development of a sense of character and connection (Gillard et al., 2011). More specifically, outdoor therapeutic camps are programs that are designed for individuals of all ages who have different kinds of special needs including, but not limited to, disabilities, illnesses, and/or disorders. In these therapeutic settings, the focus is on increasing confidence, developing character, and connecting youth with disabilities with others of similar and different abilities and disabilities. The goals of therapeutic camps align with positive youth development philosophy (Lerner et al., 2005), which seeks to improve adolescents' competence, confidence, connection, character, and contribution ("The Five Cs"; Lerner \& Lerner, 2013). The Five Cs model is well-tested and remains an established model for youth development (Arnold \& Silliman, 2017; Hamilton et al., 2004).

Support for utilizing PYD in the outdoor therapeutic camp setting comes from research by Moxham, Liersch-Sumskis, Taylor, Patterson, \& Brighton (2015) and focuses on individuals with mental illness. In this study, camp participants developed a sense of purpose enabling them to cope with the challenges associated with mental illness. Moreover, engagement in therapeutic recreation activities provides opportunities for individuals with disabilities to be able to reduce feelings of helplessness by allowing them to have control of their own choices and independence (Moxham et al., 2015; Patterson, 2007; "Benefits of therapeutic outdoor recreation," 2012). Allsop et al. (2013) also found participation in TR and camp activities has a positive influence on adolescents with chronic illness showing improvements in levels of social self-efficacy and social performance. Additional benefits associated with therapeutic camps include positive experiences of enjoyment, interest, relaxation, and freedom of choice or intrinsic motivation (Cotton \& Butselaar, 2012; Moxham et al., 2015; Patterson, 2007). Improvements in self-determination, self-confidence, family relationships, and social life have all increased due to active participation in TR activities within a camp setting as well (Anderson \& Heyne, 2012, 2013; Hebblethwaite, 2013; Moxham et al., 2015; Pilchak, 2008; "Benefits of therapeutic outdoor recreation," 2012). 
Positive Youth Development at a Therapeutic Camp

Another aspect of youth development through participation in the outdoor therapeutic camp is evident in research by Dawson and Liddicoat (2009) focusing on adults with cerebral palsy. The centrality of this study highlighted the sense of connectedness and confidence derived through opportunities for involvement as well as the emotional and social support the camp setting provides. Not surprisingly, for most of the campers who attend therapeutic camps, this is the only opportunity for them to participate in outdoor leisure settings (Dawson \& Liddicoat, 2009). Youth with disabilities who attend outdoor therapeutic camps have opportunities for positive youth development through confidence building, character development, and a sense of connectedness. Given prior research and the positive youth development model, we conducted interviews with past camp participants to identify the value of the camp experience and how it contributed to their overall development.

\section{Method}

\section{Participants}

All participants in this study were campers enrolled in a therapeutic camp located in the Southeastern United States during spring 2016. All participating youth were between 18 and 21 years old, and had attended this camp at least. Participants had a wide range of disabilities such as cerebral palsy, autism, and Down syndrome. The institutional review board at the camp's affiliated University approved this study.

\section{Camp Program}

The therapeutic camp in this study is an outdoor, therapeutic-based, residential camp for approximately 140 youth, ages seven to 21 , who have multiple disabilities. To be eligible for this camp, all campers must have more than one disability. Camper disabilities include autism, cerebral palsy, Down syndrome, Angelman's syndrome, and ADHD. The camp is a week-long residential camp held at a local accessible 4-H center in the Southeastern United States. More than 200 people staff this program and are trained specifically to work with youth with disabilities; all activities are modified to meet the camper's needs and abilities. This camp offers a one-to-one, camper-to-counselor ratio to ensure all special needs are met throughout the week of camp. Campers are assigned to a specific counselor for the duration of the week. These camper-counselor pairs are organized into cabin groups of 10 to 12 pairs. Each cabin group rotates through a sequence of activities during the day and the entire camp comes together in the evening for special events. Typical camp activities include ropes course, 
Positive Youth Development at a Therapeutic Camp

canoeing, horseback riding, arts and crafts, music and movement, exercise and yoga, and sports and games. The evening special events are typically a scavenger hunt, movie night, bonfire, carnival night, and a dance. Staff of this camp serve in the role of a counselor or an activity staff.

\section{Data Collection}

A member of the research team identified study participants based on the study criteria and contacted parents via email to gain parental consent. After receiving signed parental consent forms, the researchers scheduled each participant's interview at a convenient time for the participants during camp. Prior to the interview, an assent form was read aloud to each participant. Due to the participants' intellectual disabilities that presented as either their primary, secondary, or tertiary disability, this study employed a semi-structured interview format. The interview questions were posed to answer the following research questions:

1. What perceived benefits does camp provide for youth with disabilities?

2. In what ways does attending camp help the individual throughout young adulthood (ages 18-21)?

3. Do perceived benefits differ when looking at specific demographics with the study sample (e.g. age, gender, family composition)?

The interviews took approximately 10 to 30 minutes to complete and were recorded via voice recording device.

After the completion of all interviews, data were transcribed verbatim. To protect the identity of the participants in the study, pseudonyms were assigned by the researchers. QDA Miner software was used to organize and code the data for themes. The constant comparative method of data analysis was used for this study where the codes and themes were selected during the analysis (Ridolfo \& Schoua-Glusberg, 2011). Initially, the researchers read and coded the interview data for themes independently using QDA Miner software. The researchers then came together to discuss the themes they identified and noted differences in themes. By comparing findings from the study, new themes were formed and others were discontinued. After discussion, the researchers collaborated on the final codebook to be used. Finally, each researcher recoded the data independently using the collaborative codebook. The matching percentage of each researcher's codes were $87.5 \%$. To help ensure trustworthiness, the researchers conducted a member check. Once the results were compiled, the researchers summarized the findings into simplified language that the participants could understand. Then, each participant was contacted via email and was asked to review the summarized findings and 
provide comments on the accuracy. Only $25 \%$ of the participants responded to the member check and all verified the accuracy of the findings.

\section{Results}

A total of twelve participants were selected for the study, six were female and six were male. The participants ranged in age from 18 to $21(M=19.5, S D=1.31)$ and included disabilities such as cerebral palsy, autism, Down syndrome, attention deficit disorder, and attention deficit hyperactive disorder. Nearly all the participants lived at home with both parents $(91.67 \%)$ and had at least one sibling (33.3\%) with the majority having two or more siblings (50\%). The average number of years that the participants attended this camp was $6.58(S D=3.23)$. Tables 1 and 2 provide demographic information about the sample.

Table 1. Demographic Profile of the Sample

\begin{tabular}{|c|c|c|}
\hline Variable & N & Percentage \\
\hline Gender & & \\
\hline Male & 6 & 50.0 \\
\hline Female & 6 & 50.0 \\
\hline Age & & \\
\hline 18 & 4 & 33.3 \\
\hline 19 & 2 & 16.7 \\
\hline 20 & 2 & 16.7 \\
\hline 21 & 4 & 33.3 \\
\hline Number of Years Attended & & \\
\hline This Camp & & \\
\hline 2 & 1 & 8.3 \\
\hline 4 & 3 & 25.0 \\
\hline 5 & 2 & 16.6 \\
\hline 6 & 1 & 8.3 \\
\hline 8 & 2 & 16.6 \\
\hline 10 & 2 & 16.6 \\
\hline 13 & 1 & 8.3 \\
\hline
\end{tabular}


Positive Youth Development at a Therapeutic Camp

Table 2. Individuals' Disabilities

\begin{tabular}{|l|l|l|}
\hline Pseudonym & Primary disability & Secondary disability \\
\hline Jackie & cerebral palsy & intellectual disability \\
\hline Sarah & emotionally disturbed & learning disability; visual impairment \\
\hline Elizabeth & Down syndrome & intellectual disability \\
\hline Deborah & autism & intellectual disability \\
\hline Lacy & Down syndrome & intellectual disability \\
\hline Cecelia & cerebral palsy & cortical visual impairment \\
\hline Aaron & autism & ADHD \\
\hline Dan & autism & seizure disorder \\
\hline Gary & developmental disability & OCD; ADHD; bipolar disorder \\
\hline Carter & intellectual disability & speech impairment; shaken baby syndrome \\
\hline Sean & cerebral palsy & spastic quadriplegic \\
\hline Kevin & learning disability & apraxia \\
\hline
\end{tabular}

\section{Themes}

Upon completion of the data analysis, three themes emerged from the interviews: social, character building, and self-confidence.

\section{Social}

The first theme that occurred pertained to the social component derived from various activities and situations that present themselves at camp. This theme provides linkages to the connection domain outlined within the Five Cs of positive youth development. Being a part of camp allows the campers to be exposed to various social situations not typically experienced in their everyday lives and to situations where they are able to develop reciprocated positive bonds with others. Many campers (66.7\%) described feelings of being a part of a community by expressing that the people at camp were like a family to them. Some common responses from the campers were: "It's like a big family," "It's like a big family reunion," and "I have family here." One answer that stood out in particular came from the question, "Why do you like to come back to camp each year?" Lacy, who has been attending camp for many years, answered, "I like to come back each time because I have my friends and family here. They are like a big family of mine and I love them more than anything." When asked the same question, Jackie responded, "I think it's like what everyone says. It's like a family here at camp, you know?" 
Several campers (50\%) noted that camp also gives them the opportunity to meet new friends and to continue old friendships. In response to the question, "Has camp had an impact on your life?" Jackie said, "It's helped me build friendships with people that I wouldn't have otherwise and you get to meet people and create such a strong bond with all these people." When the campers were asked what they liked most about camp, responses included: "I have fun with my friends," "It's fun and I get to hang out with my friends," and "I have friends here that help me to become my best." One notable response was from Dan who has been attending for more than half of his life. When asked, "What have you learned at camp?" he responded, "I have learned to make friends." Not only is camp a place for youth with disabilities to meet new friends and to see old friends but it is also a place for these youths to learn how to make friends for the first time. Additionally, when asked if he had learned anything new at camp, one camper responded, "I learned that I can trust people."

\section{Character Building}

This second common theme that emerged reflects the character domain of positive youth development and relates what is learned at camp to positive changes in one's self as well as a fostered a sense of independence and individuality. A number of campers' responses (58.3\%) highlighted the character-building component of camp. When the campers were asked, "Have you learned anything new at camp and if so, what?" campers responded with: "I learned to have fun," "I learned to be nice," and "I learned to be my inner self." Jackie answered, "You learn that there are not as many limitations as you thought." Dan responded with, "I learned the very most meaning of synergy, teamwork, fellowship, and caring." When Dan was asked to elaborate on his answer a little more he stated, "Well, I basically learned who I truly am." A few other campers also said that they learned more about themselves. When Sean was asked "How do you feel when you get home after being at camp for a week?" He answered, "I'm able to be myself more." Furthermore, when the researcher asked Sean to compare the learning environment at school to the learning environment at camp, he stated, "I feel more independent at camp to do things I actually want to do."

\section{Self-Confidence}

This third and final theme pairs well with the confidence domain of positive youth development as many campers noted in their own way feelings of self-worth, mastery, and the ability to be successful. Numerous campers (25\%) named self-confidence specifically as something they 
Positive Youth Development at a Therapeutic Camp

gained from camp. When the campers were asked if camp had an impact on their life, campers responded with: "Yes, of course!" and "Yes, in many ways!" When probed with a follow-up question asking them to explain their answer in more detail, campers spoke about the impact that camp has had on their confidence level. Sarah stated, "It [camp] helped me to become more confident and it helped me to believe in me." When asked the same question, Jackie shared, "Camp has totally changed my life and has made me more confident in what I want to do with my life and just as a person in general. I've like come out of my shell even more." Not only do these campers feel more confident while they are at camp, but some also feel this way when they return home from camp. One of the questions that the campers were asked was, "How do you feel when you get home after being at camp for a week?" Lacy said, "I feel more confident with myself."

Additionally, several of the campers' responses (66.7\%) tied self-confidence to trying or learning something new. When asked if she had ever done anything new at camp that she had never done before, Jackie answered, "I've zip lined before, and I've canoed before, and I've ridden a horse before, and I've never done those things before I got to camp, and I never thought that I would ever do those things." One response that stood out was from Sarah who said, "I did canoes and the rope swing for the first time at camp. I got over my fear of heights!" A follow-up question asked Sarah to explain how that made her feel. She answered, "I used to be afraid that I would fall out because I'm clumsy. I'm not afraid of that anymore and it's one of my favorite things to do at camp now!" When the campers were asked, "Have you learned anything new at camp and if so, what?" two remarkable responses were "I learned that I can do anything," and "I learned to build my self-confidence and self-esteem."

\section{Discussion}

The purpose of this article is to describe the value of the camp experiences among youth with disabilities participating in an outdoor therapeutic camp. The primary aim of data analysis in this study was to gain more insights into the dimensions of positive youth development amongst youth campers with disabilities. Three important themes emerged from the analyses: social, character building, and self-confidence.

\section{Social}

During the week of camp, campers and staff members are together all day doing everything together. The campers received several opportunities to interact with each other as they 
Positive Youth Development at a Therapeutic Camp

reacquainted with old friends and made new ones. Campers felt as if they were at a "home away from home" and a member of the "camp" family. Moreover, socially, many campers expressed that they were "able to be themselves" and felt accepted. Studies conducted by King et al., (2003) and Milner and Kelly (2009) found that the social aspect of camp experiences was an important element in creating and maintaining community. For example, King et al. noted that a child's self-perception of his/her athletic and scholastic competence and emotional, behavioral, and social functions are important relative to membership in social circles. Similarly, Milner and Kelly (2009) found membership to be important to a youth with disabilities' sense of community. Finally, one of the significant findings of Milner and Kelly's study that relates to the present research effort is that participants gravitated towards relationships and leisure-based programs where they felt known. Both factors helped to increase the participants' social identity as well as heighten their sense of belonging.

\section{Character Building}

Character building is an important part of positive youth development (Allsop et al., 2013). In this study, campers stated that they felt as if they were able to do what they wanted while at camp as long as they followed certain rules. They also claimed that participation in the camp experience helped them to become more independent and autonomous in their decision making. Studies by Moxham et al. (2005) and Patterson (2007) revealed similar findings when they noted that therapeutic recreation activities provided opportunities for individuals with disabilities to be able to reduce feelings of helplessness by allowing them to have control of their own choices and independence. By teaching the campers daily living skills that some of them have never been taught, the campers start to feel and know that they have the capability to be more independent in their everyday lives. Furthermore, Zuwarski (2015) concluded that "self-determination as a facet of character building can be strengthened through building skills associated with autonomous functioning, which include: self/family care, life management skills, and fulfilling personal responsibilities" (p. 84). Similarly, Sheppard and Unsworth (2011) argued that participation in recreation and leisure activities and involvement in social and vocational activities are essential to character building for youth with disabilities.

\section{Self-Confidence}

In this study, one of the meaningful benefits that emerged was that campers expressed feelings of more self-confidence. Several studies reinforce the value of recreation in camp settings for youth and adults with disabilities relative to self-confidence. Studies conducted by Anderson and 
Heyne (2012, 2013), Hebblethwaite (2013), Moxham et al. (2015), and Pilchak (2008) reported outcomes such as improvements in self-determination, self-confidence, family relationships, and social life as a function of active participation in therapeutic recreation activities within a camp setting. Moreover, in this study, after leaving camp, the campers left feeling more confident in themselves, which can directly affect their social life.

Additionally, Shelton's 2011 study found that therapeutic camps afford young people the opportunity to experience the outdoors, and participate in activities that are "outside the norm," such as canoeing, climbing a challenge course, boating, arts and crafts, and other experiences. Campers in this study participated in similar outdoor activities that included ropes courses, canoeing, bike riding, and horseback riding. For many of the campers this was their inaugural opportunity to participate in these types of outdoor recreational pursuits.

\section{Value of the Themes}

The three themes, social skills, character building and self-confidence are valuable within and beyond the camping experience. Each of these themes helps to lay the groundwork for success beyond the outdoor camp experience. For example, Shogren, Wehmeyer, Palmer, Rifenbark and Little (2015) suggest that, for youth with disabilities, social skills, character building, and selfconfidence are essential to a heightened level of self-determination, which is valuable to being successful in achieving employment and navigating the communities in which they will live, work, and play. This is akin to the position of Shogren et al. (2015), and Lindsay, McDougall, Menna-Dack, Sanford, and Adams (2015), who suggest that appropriate social development, character, and self-confidence will help youth with disabilities overcome some of the individual, socio-structural (e.g., social and organizational structures in society) and environmental barriers to employment. Having good social skills, good character and the self-confidence attained from successful experiences in the camp environment may yield transferable outcomes. Tasks such as learning to follow directions completing assigned tasks and the development of personal routines may later translate into the ability to navigate public transportation lines to get to work on time or complete personal and team-related tasks in the work environment. These tasks are needed to successfully gain and sustain employment, care for oneself and become one's own advocate (Lindsay et al., 2015). Finally, the three themes identified in this study are valuable because they potentially play a role in shaping the leisure preferences and behaviors of the youth over their lifespan, depending on the severity of the disability and the availability of family and community support systems (Johnson \& Bagatell, 2017; Ratcliff, Hong, \& Hilton, 2018). 


\section{Conclusion}

\section{Limitations}

While every effort was made to be thorough in the design of this study, some limitations were beyond the control of the researchers and can be reasonably explained by the study participants' characteristics. One limitation pertains to the lack of depth in participant responses to the interview questions. Some answers were very short or one-word responses. There were several instances where the participants replied with "I don't know" even after questions were reworded by the interviewer. It is plausible that due to participants' intellectual disability, they had difficulty comprehending the questions. Another limitation was the challenges the researchers faced in deciphering and comprehending the participant responses, which resulted in unusable data. Additionally, the thoroughness of the member check was limited by the response rate and potentially participants' intellectual disabilities. The final limitation is the limited generalizability of the study. This study focused on the camp experiences from one therapeutic camp in the Southeastern United States. No other camp programs were researched as part of this study; therefore, the findings cannot be generalized to other therapeutic camp settings.

\section{Implications for Practice}

There are several challenges that are faced with this type of camp design that should be mentioned for practitioners attempting to replicate this camp program. One of the greatest privileges of this camp is the ability to offer a one-to-one camper-to-counselor ratio. While this is unusual for many camps, this ratio provides the opportunity to meet the needs of campers who have significant medical issues; however, the large numbers of staff required can present a challenge for practitioners. Also, since the campers range in age from 7 to 21 , creating therapeutic activities that meet the diverse needs and mental ages is also challenging. Within the same vein, therapeutic camp activities require program plans that have specific goals and objectives that are geared towards campers' strengths and limitations. Staff trained in therapeutic recreation are integral to ensuring quality programming as they are not only equipped with this skill set but are trained in working in with individuals with disabilities who have special needs. One of the greatest challenges of this camp is finding a camp location that is not only large enough to accommodate the 140 campers and over 200 staff members but one that is also accessible. 
One of the positive lessons learned from attending the outdoor therapeutic camp is the importance of benefits-based youth development for youth with disabilities. The implementation of benefits-based management (BBM) as a means to obtain the desired outcomes for youth and the organization can be invaluable. Benefits-based management is an outcomes-focused management system that utilizes a planning model to intentionally target the benefits that accrue to individuals and communities from participation in recreation initiatives (McLean \& Hurd, 2015). In the case of the participants in the present study, the initiative is outdoor recreation.

Relatedly, there is an opportunity to understand the role of supportive adult staff in helping youth with disabilities navigate from negative to positive views of nature, as well as obtaining needed competencies for successful outdoor experiences (Lekies, Yost, \& Rode, 2015). In this study, campers experienced several benefits. Among these benefits were increased social interaction, physical activity, and self-confidence as well as character building through increased independence. Understanding and knowing the benefits that a meaningful outdoor recreation experience in a camp setting can provide for participants is important for youth development and therapeutic recreation practitioners in order to develop programs that maximize the benefits to participants. Moreover, the sheer experience of participating in an outdoor therapeutic camp may serve to help staff recognize that youth with disabilities may have differing perceptions of the outdoors. Inherently, some will arrive with positive or negative viewpoints about nature and outdoor recreation and therein lies the opportunity for creative programming that helps foster positive attitudes about recreating in outdoor settings.

\section{References}

Allsop, J., Negley, S., \& Sibthorp, J. (2013). Assessing the social effect of therapeutic recreation summer camp for adolescents with chronic illness. Therapeutic Recreation Journal, XLVII(1), 35-46.

Anderson, L. S., \& Heyne, L. A. (2012). Flourishing through leisure: An ecological extension of the leisure and well-being model in therapeutic recreation strengths-based practice. Therapeutic Recreational Journal, 46(2), 129-152.

Anderson, L. S., \& Heyne, L. A. (2013). A strengths approach to assessment in therapeutic recreation: Tools for positive change. Therapeutic Recreation Journal, 47(2), 89-108. The benefits of therapeutic outdoor recreation. (2012). SouthSource. Retrieved from http://source.southuniversity.edu/the-benefits-of-therapeutic-outdoor-recreation-102985.aspx 
Journal of Youth Development | http://jyd.pitt.edu/ | Vol. 14 Issue 1 DOI 10.5195/jyd.2019.634

Positive Youth Development at a Therapeutic Camp

Arnold, M. E, \& Silliman, B. (2017). From theory to practice: A critical review of positive youth development program frameworks. Journal of Youth Development, 12 (2), 1-20. doi:10.5195/jyd.2017.17

ATRA. (n.d.). About recreational therapy. Retrieved from https://www.atraonline.com/page/AboutRecTherapy

Centers for Disease Control and Prevention. Data \& statistics. Retrieved February 18, 2015, from http://www.cdc.gov/ncbddd/autism/data.html

Cotton, S. M., \& Butselaar, F. J. (2012). Adventure camps for young adults and adults with mental illness. Psychiatric Services, 63(11), 1154. doi:10.1176/appi.ps.1154

Dawson, S., \& Liddicoat, K. (2009). "Camp gives me hope": Exploring the therapeutic use of community for adults with cerebral palsy. Therapeutic Recreation Journal, XLIII(3), 9-24.

Duerden, M. D., Widmer, M. A., \& Witt, P. A. (2010). Positive youth development: What it is and how it fits in therapeutic settings. Journal of Therapeutic Schools \& Program, 4(1), 118-133

Gillard, A., Witt, P., \& Watts, C. (2011) Outcomes and processes at a camp for youth with HIV/AIDS. Qualitative Health Research, 21 (11), 1508-1526. doi:10.1177/1049732311413907

Hamilton, A., Mazzucchelli, T. G., \& Sanders, M. R. (2015). Parental and practitioner perspectives on raising an adolescent with a disability: A focus group study. Disability \& Rehabilitation, 3718), 1664-1673. doi:10.3109/09638288.2014.973969.

Hamilton, S., Hamilton, M., \& Pittman, K. (2004). Principles for Youth Development. In S. Hamilton \& M. Hamilton (Eds). The youth development handbook: Coming of age in American Communities (pp. 3-22). Thousands Oaks, CA: Sage.

Hebblethwaite, S. (2013). "I think that it could work but . . .": Tensions between the theory and practice of person-centered and relationship-centered care. Therapeutic Recreation Journal, 4Л1), 13-34.

Johnson, K. \& Bagatell, N. (2017) Beyond custodial care: Mediating choice and participation for adults with intellectual disabilities, Journal of Occupational Science. 24(4), 546-560. doi:10.1080/14427591.2017.1363078

King, G., Lawm, M., King, S., Rosenbaum, P., Kertoy, M. K., \& Young, N. L. (2003). A conceptual model of the factors affecting the recreation and leisure participation of children with disabilities. Physical \& occupational therapy in pediatrics, 23(1), 63-90.

Lekies, K. S., Yost, G., \& Rode, J. (2015). Urban youth's experiences of nature: Implications for outdoor adventure recreation. Journal of Outdoor Recreation and Tourism, 9, 1-10. doi:10.1016/j.jort.2015.03.002

Lerner, R. M., \& Lerner, J. V. (2013). The positive development of youth: Comprehensive findings from the 4-H study of positive youth development. Washington, DC: National 4-H Council. Retrieved from https://4-h.org/wp-content/uploads/2016/02/4-H-Study-of-Positive-Youth-DevelopmentFull-Report.pdf 
Journal of Youth Development | http://jyd.pitt.edu/ | Vol. 14 Issue 1 DOI 10.5195/jyd.2019.634

Positive Youth Development at a Therapeutic Camp

Lerner, R. M., Lerner, J. V., Almerigi, J., Theokas, C., Phelps, E., Gestsdottir, S., . . von Eye, A. (2005). Positive youth development, participation in community youth development programs, and community contributions of fifth grade adolescents: Findings from the first wave of the 4-H Study of Positive Youth Development. Journal of Early Adolescence, 25(1), 17-71. doi: $10.1177 / 0272431604272461$

Lindsay, S., McDougall, C., Menna-Dack, D., Sanford, R. \& Adams, T. (2015). An ecological approach to understanding barriers to employment for youth with disabilities compared to their typically developing peers: Views of youth, employers, and job counselors. Disability and Rehabilitation. 37(8), 701-711. doi:10.3109/09638288.2014.939775

McLean, D. D. \& Hurd, A. R. (2015). Kraus' recreation and leisure in modern society (10 ${ }^{\text {th }}$ ed.). Burlington, MA: Jones \& Bartlett Learning.

Milner, P., \& Kelly, B. (2009). Community participation and inclusion: People with disabilities defining their place. Disability \& Society, 24(1), 47-62. doi:10.1080/09687590802535410

Moxham, L., Liersch-Sumskis, S., Taylor, E., Patterson, C., \& Brighton, R. (2015). Preliminary outcomes of a pilot therapeutic recreation camp for people with a mental illness. Therapeutic Recreation Journal, 49(1), 61-75.

Patterson, I. (2007). Changes in provision of leisure services for people with disabilities in Austrailia. Therapeutic Recreation Journal, 41(2), 108-118.

Pilchak, H. L. (2008). Mental health benefits of therapeutic riding programs (Unpublished doctoral thesis). Univsersity of Toronto, Canada.

Ratcliff, K., Hong, I. \& Hilton, C. (2018). Leisure participation patterns for school age youth with autism spectrum disorders: Findings from the 2016 national survey of children's health. Journal of Autism Developmental Disorders. 48(1), 3783-3793. doi:10.1007/s10803-018-3643-5

Ridolfo, H., \& Schoua-Glusberg, A. (2011). Analyzing cognitive interview data using the constant comparative method of analysis to understand cross-cultural patterns in survey data. Field Methods, 23(4), 420-438. doi:10.1177/1525822X11414835

Shelton, K. (2011). Therapeutic camps as respite care providers. Therapeutic Recreation Journal, 45 (1), 17-31.

Sheppard, L., \& Unsworth, C. (2011). Developing skills in everyday activities and self-determination in adolescents with intellectual and developmental disabilities. Remedial and Special Education, 32(5), 393-405. doi:10.1177/0741932510362223

Shogren, K. A., Wehmeyer, M. L., Palmer, S. B, Rifenbark, G. G., \& Little, T. D. (2015). Relationships between self-determination and postschool outcomes for youth with disabilities. The Journal of Special Education, 48(4), 256-267. doi:10.1177/0022466913489733 
Journal of Youth Development | http://jyd.pitt.edu/ | Vol. 14 Issue 1 DOI 10.5195/jyd.2019.634

Positive Youth Development at a Therapeutic Camp

Zuwarski, M. E. (2015). Perspectives on a positive youth development environment for youth with developmental disabilities in $4-\mathrm{H}$. Retrieved from http://digitalcommons.spu.edu/cgi/viewcontent.cgi?article=1001\&context=cpy_etd 